\title{
Critérios de decisão na ilusão da máscara côncava na esquizofrenia
}

Decision criteria in the concave mask illusion in schizophrenia

DOI: 10.1590/0047-2085000000278

J Bras Psiquiatr. 2020;69(3):143-8

Where you read:

Received in: Mar/26/2020. Approved in: Apr/27/2020

Should read:

Received in: Jun/07/2019. Approved in: Mar/26/2020

DOI: 10.1590/0047-2085000000318 